Ernst / Annerl / Ernst · Rationalität, Gefühl und Liebe im Geschlechterverhältnis 
Soziologische Studien

Band 15 


\section{Rationalität, \\ Gefühl und Liebe im \\ Geschlechterverhältnis}

Ursula Marianne Ernst

Charlotte Annerl

Werner W. Ernst

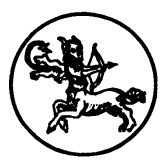

Centaurus Verlag \& Media UG 1995 
Zur Umschlagabbildung:

Eurydike und Orpheus 1995

Oder: Bosch-auf-Münter-Schnittwerk

Collage, Anna Koslowski

Die Deutsche Bibliothek - CIP-Einheitsaufnahme

Rationalität, Gefühl und Liebe im Geschlechterverhältnis /

hrsg. von Ursula Marianne Ernst ... - Pfaffenweiler :

Centaurus-Verl.-Ges., 1995

(Soziologische Studien ; Bd. 15)

ISBN 978-3-8255-0071-9 ISBN 978-3-86226-452-0 (eBook)

DOI 10.1007/978-3-86226-452-0

NE: Ernst, Ursula Marianne [Hrsg.]; GT

\section{ISSN 0937-664X}

Alle Rechte, insbesondere das Recht der Vervielfältigung und Verbreitung sowie der Übersetzung, vorbehalten. Kein Teil des Werkes darf in irgendeiner Form (durch Fotokopie, Mikrofilm oder ein anderes Verfahren) ohne schriftliche Genehmigung des Verlages reproduziert oder unter Verwendung elektronischer Systeme verarbeitet, vervielfältigt oder verbreitet werden.

(C) CENTAURUS-Verlagsgesellschaft mit beschränkter Haftung, Pfaffenweiler 1995

Satz: Charlotte Annerl, Ursula Marianne Ernst 


\section{Inhalt}

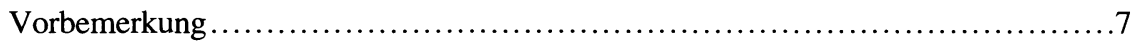

Werner W. Ernst

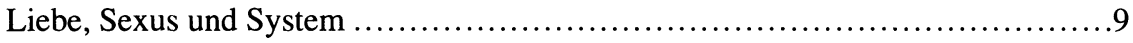

Mona Singer

Der Körper als Baustelle. Über die neuen Technologien und die

Geschlechterdifferenz...................................................... 24

Herbert Hrachovec

Intimität in der Mailbox

Anna Bergmann und Bettina Recktor

Ein Gespräch über die sexuelle Revolution und die Pille-essende Frau

mit Nebenwirkung .

Wolf Maria

Frauen sind anders. Geschlechter-Trennung als Raum eines endlosen

Versprechens.

\section{Andrea Grisold}

Reflexionen über die Funktionalität des Unerklärlichen: Beziehungen

am Ende des 20ten Jahrhunderts

Gertrude Postl

'Rationalität' und 'Gefühl' im feministischen Diskurs. Zur

Bewahrung und Überwindung eines Erklärungsmodells.

Charlotte Annerl

Der tägliche Kampf. Zur philosophischen Analyse der Unlebbarkeiten

im modernen Geschlechterverhältnis.....

Bernd Nitzschke

Von der Allmacht der Mütter, der Ohnmacht der Väter und der

Übermacht des "männlichen" Prinzips.

Claudia von Werlhof

Freud-los?.....

Bernhard Tilg

Der Körper, die Maschine, der Sex und die Liebe

Ursula Marianne Ernst

Selbsterkenntnis als Selbstpreisgabe im Namen einer höheren Liebe

Selinde Böhm

Der platonische Eros zwischen Logos und Sinnlichkeit. Zum Problem

geschlechtsspezifischer Diskurse

Astrid Meyer-Schubert

Das weibliche Gewissen. Zum Problem der Ungeschichtlichkeit des

Mutterbildes.

Autoren und Autorinnen 